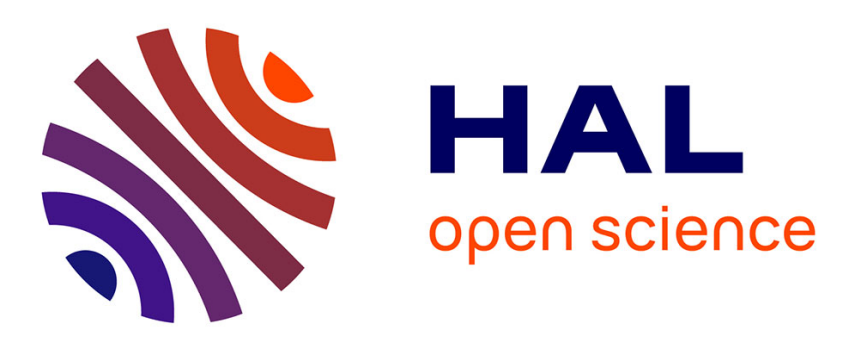

\title{
The robustness of the round planning face to risks of road freight transport
}

\author{
Antoine Clément, Daouda Kamissoko, François Marmier, Didier Gourc
}

\section{To cite this version:}

Antoine Clément, Daouda Kamissoko, François Marmier, Didier Gourc. The robustness of the round planning face to risks of road freight transport. GOL 2018 - 4th IEEE International conference on Logistics Operations Management, Apr 2018, Le Havre, France. hal-01800316

\section{HAL Id: hal-01800316 https://hal.science/hal-01800316}

Submitted on 19 Nov 2018

HAL is a multi-disciplinary open access archive for the deposit and dissemination of scientific research documents, whether they are published or not. The documents may come from teaching and research institutions in France or abroad, or from public or private research centers.
L'archive ouverte pluridisciplinaire HAL, est destinée au dépôt et à la diffusion de documents scientifiques de niveau recherche, publiés ou non, émanant des établissements d'enseignement et de recherche français ou étrangers, des laboratoires publics ou privés. 


\section{The robustness of the tour planning face to risks of road freight transport}

\author{
Antoine Clement \\ Industrial Engineering Laboratory \\ IMT Mines Albi, Toulouse University \\ 81000 Albi, France \\ aclement@mines-albi.fr
}

Didier Gourc

Industrial Engineering Laboratory

IMT Mines Albi, Toulouse University

81000 Albi, France

dgourc@mines-albi.fr

\author{
Daouda Kamissoko \\ Industrial Engineering Laboratory \\ IMT Mines Albi, Toulouse University \\ 81000 Albi, France \\ dkamissoko@mines-albi.fr
}

\author{
François Marmier \\ Industrial Engineering Laboratory \\ IMT Mines Albi, Toulouse University \\ 81000 Albi, France \\ fmarmier@mines-albi.fr
}

\begin{abstract}
Currently, over $90 \%$ of goods are transported by road terrestrial mode. To progress, companies of Road Freight Transport sector (RFT) are subject to a number of issues, whether economic, regulatory, environmental, societal, occupational health and safety ... The planner has a crucial role in achieving these challenges, it is he who undertakes the construction method of the tours, for the future of the company. Thus he bears a heavy responsibility on his shoulders. Its ability to integrate the company's constraints and to master the balance between these issues in the construction of tour is vital. However a list of risks is potentialy present and can affecte his planning. This lack of vision about risks impact prevents him to achieve his mission. Thus we propose in this article a mean to qualify the tours generated in relation to the issues mentioned but also in terms of potential hazards that could come impair the quality of tours. In this article, we propose an evaluation process of road transport of goods tours and an indicator to measure the robustness of touring.

Index Terms — risk, assessment, decision, tour, robustness
\end{abstract}

\section{INTRODUCTION}

Nowadays, more than $90 \%$ of goods are conveyed by road. Road Freight Transport (RFT) companies therefore embody a sector of capital importance to the French economy; they represent an annual turnover of 44 billion euros, which is generated by more than 37,200 companies (more than $90 \%$ of companies in this sector are SMEs/VSEs with less than 50 employees) and roughly 420,000 employees. This sector is characterized by strong competition and growing pressure from customers and suppliers, tight delivery times, exacerbated flexibility, etc. (economic stakes). RFT companies are also subjected to specific national and community standards and regulations (regulatory and environmental stakes). In parallel, they are required to fulfil performance duties in terms of preventing risks of occupational accidents and diseases (article L4121-1 of the French labor code) (occupational health-safety issues). Simultaneous consideration of these three obligations has led to adoption of the term "sustainable transport systems".

There are Transport Management System (TMS) aids that ease the pressure on the planner, but these only partially integrate the area of sustainable transport operations. TMSs are generic solutions mainly aimed at transport companies that deliver to regular customers. These solutions are unsuitable for integrating specific characteristics and for the diversity of customer demands, to which the transport company must respond, if it is not to lose the contract. Such solutions do not allow fleets of mixed vehicles to be managed (optimization of vehicle selection based on its energy autonomy and/or city/town center, suburban or regional customer locations). Driver allocation to delivery rounds is not systematically integrated into TMSs, although it is crucial to limit driver overtime and to equitably distribute workload among drivers. Ultimately, TMSs mostly ignore both health and safety aspects and consideration of different combined energies. Moreover, these aids are relatively expensive because they are usually divided into modules or systems; a purchase or subscription is required for each module, function or hardware item (the average cost of a rented module being 30 euros/month/truck and a module does not operate separately). Yet, cost is a major constraint, especially for VSEs/SMEs. All these curbs (unsuitability to customer diversity, to mixed fleets, no overtime management, cost of systems) oblige many VSEs/SMEs to perform their planning using a spreadsheet, a word processing program or even pencil and paper.

New proposals are required for planning sustainable transport services and these must take into account the financial, environmental and social issues.

Besides taking criteria into account for the quality evaluation of the generated tours, we would also propose solutions to integrate the measurement of the robustness of the solution to potential risks that could alter the planning done. In front of the complexity of its task, we should be able to suggest the planner some indicators to facilitating the selection and the choice of the best solution. Among these indicators, we propose to build a representative indicator of the confidence that can be attributed to a solution. By confidence we mean the ability of this solution to keep the commitments made, for 
example with the customer or compliance with the maximum working time (time amplitude of the tour).

This article is divided into 5 parts. In section 2, we present a state of art for the selected issue. In section 3, the part of the methode to describe the work developed to address the problem. Section 4 contains an example to illustrate the proposals made. To finish, the conclusion takes stock of the situation and provides some ideas for complete this work.

\section{STATE OF THE ART}

\section{A. Related work about risk analysis}

For several years, we have led, in our laboratory, research dealing with the theme of analysis and control of risks in the project and process management. These works led to the development of innovative proposals based on the RIO model [1, 2, 3]. These works aim to take into account all combinations of occurrence risks and their influence on schedules. Scenarios of schedules thus generated are evaluated according several criteria: probability of occurrence, duration, cost, and any other specific criteria for a type of evaluated schedule.

In the literature, risk management methods refer to a standard process with well-known steps: identification, assessment, quantification, treatment and risk monitoring [4]. [5] propose a classification with 62 existing approaches. Methods are sorted depending on whether they are deterministic and/or probabilistic, but also qualitative or quantitative. Gourc et al. offer a grid of different reading, classifying approaches of risk management whether they are symptomatic or analytical [6]. The first group of approaches, also called risk-uncertainty is associated with approaches where the project risk management is converted into managing uncertainty [7]. The second group of approaches views risk as an event that may affect the achievement of project objectives [8].

Two themes are well known for their reference to innovation and by the omnipresence of risk: (1) the project management of new product development (NPD) at an operational level. It consists of choosing an exclusive orientation as a development strategy. It considers a level of global tolerance of risk. (2) NPD portfolio management at a tactical level. A first definition of portfolio management is given by [9]: a dynamic of decision making that enables the list of projects to be always updated. In this process, new projects are evaluated, selected and sorted. Past projects can be accelerated, stopped, or paused and resource assignments can be modified in order to build a balanced portfolio of innovative projects, on a balance risk / profitability.

Representations of project plan and tour are wery simimar, all of them can be modelised with activity networks. So, we hypothesize that concepts and software tools developped on project risk management by our research team since a few years are totally relevant for assessment of the robustness of tour in transport sector.

\section{B. Metric to assess the planning robustness}

In the literature, the robustness notion is sometime used to talk about algorithm. But this review is based on the robustness of solutions.[10] point out that there is no unique definition of the term robustness. To qualify solutions, several authors propose definitions of robustness ([11, 12, 13]) define the robustness as the aptitude to which a system can function correctly in the presence of inputs different from those planned. $[14,15]$ describe that the concept of robustness should be defined for a given set of features and under a given set of possible disturbances. There is important to note that the Society for Risk Analysis recently proposed a definition of robustness[16]. A system is robust to perturbations when goals can be achieved despite disturbances occur.

In the context of transport plannification, robust planning is defined as a planning that is insensitive to disturbances that might occur during the implementation of planned activities. The definition of a robustness metric aimed to measure the sensitivity/insensitivity of the planning to potential disturbances. The robustness can be assess using metrics. Those metrics must enable to reflect a-priori the planning's capacity of the tour to respect objectives or requirements that we define as the contractual space. Thus, in our context, the contractual space will be defined, for instance, by the tour's maximum working time, the maximum time for each driving period, etc.

The directed acyclic graphs can be used to model schedules and, by extension, tour transport's schedules. In the context of planning for directed graphs acyclic, [17] offer two definitions of the robustness and propose two expression of the robustness. The first is expressed by the multiplicative inverse of the expected value of relative schedule tardiness. The second is calculated by the multiplicative inverse of schedule miss rate.

This work addresses primarily deterministic graphs. For our problem, we are led to consider the probability of occurrence of hazards during the tour. These hazards can modify some characteristics of the graphs (duration of activities, modification of some links).

[18] and [19] propose a comparative analysis of several metric robustness. Metrics are:

- "makespan standard deviation"

- "makespan differential entropy"

- "slack mean"

- "probabilistic metric"

- "lateness likelihood"

- "makespan 0,99-quantile"

[20] and [21] also provide metrics taking the dynamic nature of environment into account for which schedules are generated. The robustness is expressed as the probability that the task performed, i.e. the tour, is finished in accordance with constraints, for instance the total duration or the delivery time.

\section{PROPOSALS}

Based on the results we obtained earlier, particularly in the ANR project PLAS'O'SOINS [22] related to the tour's planning of health workforce for the maintenance of patient 


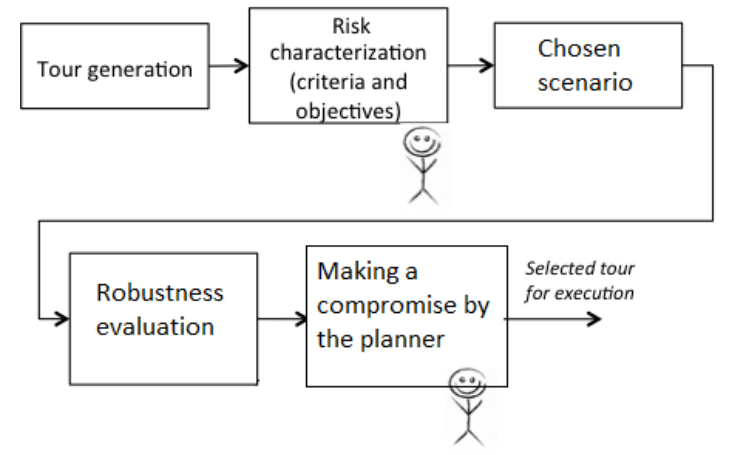

Figure 1. Proposed approach

at home [23] and our works on R-IO. The aim of the project PLAS'O'SOINS was to improve the actor's planification in health field with take in consideration risks. We propose to evaluate the quality of schedules generated by relying on the measure of possible scenarios induced by the possible occurrence of the identified hazards. For this purpose, we implement the ProRisk model on the schedule of activities concerning a tour.

\section{A. Suggested approach}

The proposed approach (Figure 1) consists of 5 steps. The first step consists in building schedules tours to serve the identified orders. Thus, on the basis of received orders, this step enables to produce a tour schedule set represented by process $\mathrm{P}$ described by their tasks $T_{i},(i=1 \ldots t)$. Based on the identified generic risks and planned activities in these processes, step 2 produces a list of specific risks for each tour and generates all the possible risk scenarios. In step 3 the planner choose plannings thus he wants to evaluate accord criteria selected. In step 4, the robustness are calculated to determine a other indicator, probability of commitments' respect, for each tour initially generated by step 1. Finally, step 5, conducted by the planner, aims to select the tour that best meets these requirements

\section{B. Model proposal}

A tour is presented as a process $\mathrm{P}$ composed by its tasks $T_{i},(i=1 \ldots t)$, where $t$ is the number of tasks (Figure 2). A tour, mobilizing a vehicle and a driver, is a process involving a succession of activities alternating with:

- starting activity, corresponding at the begin of the tour with loading of the vehicle and preparing;

- driving activities, corresponding at all mouvment to connect two points, warehouses or on a delivery points;

- waiting activities, corresponding at the time to wait before delivery a site;

- activities on site (AoS), corresponding at loading and unloading goods on site and administratif part;

- closing activity, corresponding at the end of the tour with unloading goods and cleanning the vehicle.

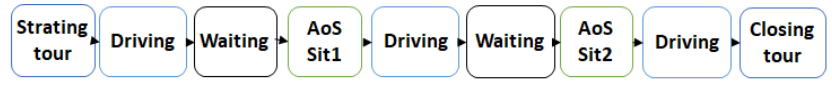

Figure 2. example of process

A tour is considered feasible or acceptable if it meets a set of constraints $C$. The constraints can include for example the respect of a maximum duration of the tour, the respect of a time slot to a client, etc.

A tour is represented as a process $\mathrm{P}$ described by its tasks $T_{t},(t=1 \ldots T)$, where $T$ is the number of tasks. The planning process provides a baseline $P_{i}$ which does not include the risks. A set of critical resources $(E R C)$ is required to process certain tasks. A process is also described by its set $E R$ of identified risks $R_{i},(i=0 \ldots n)$, where $\mathrm{n}$ is the number of risks. Each $R_{i}$ is characterized through the risk management process. A risk $R_{i}$ is also characterized by its occurrence period, namely the tasks where the risk can occur. Its probability $\operatorname{proba}\left(R_{i}\right)$ is the probability that the event related to $\mathrm{Ri}$ happens. Its impacts on costs are rated $C I\left(R_{i}\right)$ and the project duration $D I\left(R_{i}\right)$. The impacts may affect, by the domino effect, a different task from the one characterizing the period of occurrence. These probabilities and impacts are also named initial probability and initial impact. A risk scenario $S c R$ corresponds to the combination of $\mathrm{S}$ risks occurring during a process P. A process with $\mathrm{n}$ risks leads to $2^{n}$ risk scenarios. $S c R_{s},\left(s=1, \ldots, 2^{n}\right)$ is one possible implementation with $k$ risks $(0 \leq k \leq n)$. The total number of risk scenarios, presenting $\mathrm{k}$ risks is equal to $n ! / k(n-k)$ !. Its probability is noted $\operatorname{proba}\left(S c R_{s}\right)$ (the probability that the events related to this risk scenario occur and other risks do not occur). Depending on type of tasks composing the process, certain generic risks can be identified, see Table I for an example.

A risk can have an impact on the strong constraints and thus make a scenario become not feasible but it also simply affect the indicators without modifying its feasibility.

Based on these hypothesis, we are implementing a ProRisk analysis process allowing to generate all possible scenarios and calculate the indicators characterizing each scenario. The aim is, first, to determine the probability of occurrence of risk scenario proba $\left(\right.$ proba $\left(S c R_{s}\right)$. This probability of the scenario depends on the combination of risks in this scenario (Equation 1).

$$
\operatorname{proba}\left(S c R_{s}\right)=\prod_{i=1}^{n}\left\{\begin{array}{ll}
\operatorname{proba}\left(R_{i}\right) & \text { if } R_{i} \in S c R_{s} \\
1-\operatorname{proba}\left(R_{i}\right) & \text { if } R_{i} \notin S c R_{s}
\end{array}\right\}
$$

Beside the occurrence probability of a scenario, we characterize each scenario by other indicators. Very typically, the time and cost indicators are mobilized to effect this characterization. Thus, for each identified scenario, its duration and its cost are calculated. The expression of the cost calculation is shown in Equation 2. The project scenario cost is named $C(S c R s)$. It includes the cost of tasks $C(T t)$ which constitute 
Table I

EXAMPLES OF GENERIC RISKS DEPENDING ON THE TYPE OF TASKS

\begin{tabular}{|c|c|c|}
\hline Task type & Example of generic risks & Possible cause(s) \\
\hline \multirow[t]{4}{*}{ Activity on site } & Accident / injury of the driver & $\begin{array}{l}\text { Missing operator in charge of handling } \\
\text { Handling equipment not available }\end{array}$ \\
\hline & Mistake & Client is absent \\
\hline & & Handling equipment not available \\
\hline & Accident / injury of the driver & $\begin{array}{l}\text { Missing operator in charge of handling } \\
\text { Handling equipment not available }\end{array}$ \\
\hline \multirow[t]{5}{*}{ Driving } & Driver vigilance drop & $\begin{array}{l}\text { Loading/Unloading realized by the driver more important than esti- } \\
\text { mated }\end{array}$ \\
\hline & $\begin{array}{l}\text { Insufficient autonomy of the vehicle, especially for } \\
\text { vehicles with green power electric only, gas only). }\end{array}$ & $\begin{array}{l}\text { Long driving period } \\
\text { Extension of certain time (traffic jam, lowered performance of the } \\
\text { energy source, e.g. battery) }\end{array}$ \\
\hline & Accident / injury of the driver & Driver tiredness \\
\hline & & Technical problem \\
\hline & & Accident caused by a third \\
\hline
\end{tabular}

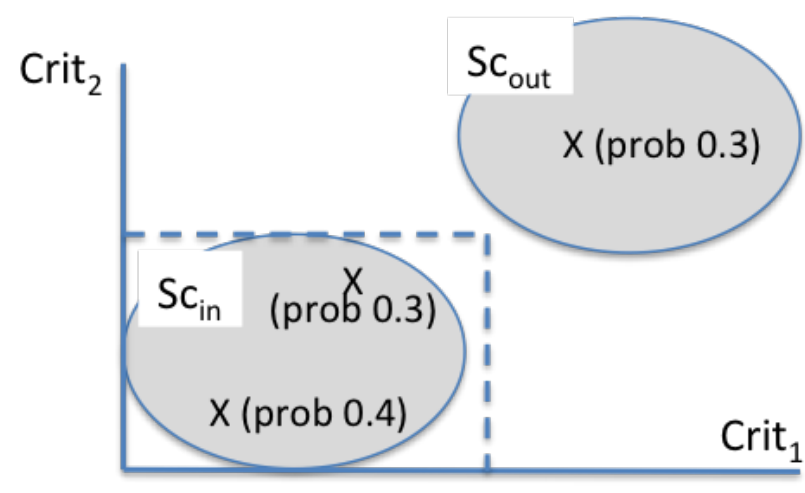

Figure 3. Illustration of $S c_{i n}$ and $S c_{o u t}$ sets

the initial planning process, impacts of occurrence risks, i.e. risks present in $S c R_{s}$, on the process tasks and the global cost $G C^{\text {initial }}\left(R_{i}\right)$ of occurring risks. $G C^{\text {initial }}\left(R_{i}\right)$ is the aggregation of risk impacts on the cost criterium. This includes a fixed portion of the total cost (materials, tools, parts, etc.) and indirect costs depending on the duration of action of each possible impact of risk

$$
C\left(S c R_{s}\right)=\sum_{t=1}^{T} C\left(T_{t}\right)+\sum_{t}^{R_{i} \in S c R_{s}} G C^{\text {initial }}\left(R_{i}\right)
$$

\section{Expression of the level of robustness}

As a first approach, we propose to define a robustness indicator of each tour planning as the measure of the ability to respect contractual space expressed by the defined constraints. Thus, robustness $R o(i)$ of the tour $i$, will represent the probability to respect this set of constraints $C o$. It is obtained from the occurrence probabilities of risk scenarios $S c R_{s}$, which respect constraints $C o$. This set of scenarios will be named $S c_{i n}$ (Figure 3).

$$
R o(i)=\sum_{S c R_{s} \in S c_{i n}} \operatorname{proba}\left(S c R_{s}\right)
$$

At this stage, this expression represents a first formulation of a robustness indicator. We expect to offer a finer indicator to weight the importance of the scenarios that don't respect the constraints and maybe take in consideration indicators limits.

\section{NUMERICAL APPLICATION}

\section{A. Description of the example}

For half a day planning, our partner may have to deliver three customers with one vehicle up to 200 customers with 20 vehicles. To illustrate our proposals, we consider an example situatein a low range of a real planning with 4 delivery points $\left(S i{ }_{j}\right)$ and two couple vehicle, driver. We consider that vehicle are different the first one is an electrical vehicul and the second one is a diesel vehicle. These four delivery points are spread over a geographical area compatible with the vehicle's energy. The vehicle is stored in a warehouse $\left(W_{1}\right)$, which also stores a portion of workpieces. Each point, warehouse and delivery point, can potentially be a place where loading and unloading's actions of the vehicle will be to achieve.

The list of orders to be processed is shown in the table (Table III). There are three orders starting at the warehouse and one where the picking point is the $\mathrm{Sit}_{3}$.

For each order are described:

- The place of loading of objects to transport (Origin);

- The place of unloading of objects to transport (Dest.);

- The loading time and unloading time calculated based on quantity;

- Time window where the driver can delivery goods.

Additional information can be mobilized, such as:

- Characteristics of the objects to be transported: volume in liter (Vol.), mass in $\mathrm{kg}$, number of objects to be transported (Qty) per unit carton/ pallet.

\section{- Presence of dock.}

Two generic risks are considered, as described in Table II. The risk $R_{1}$ expresses the effects of the traffic jam when accessing to $\mathrm{Sit}_{3}$. The risk $\mathrm{R}_{2}$ reported at a possible absence of the handler from his workplace if the delivery takes place between $10 \mathrm{~h} 00$ am and $10 \mathrm{~h} 30 \mathrm{am}$. It is frequent, but not systematic, the handler in charge of loading / unloading the 
Table II

LIST OF GENERIC RISKS

\begin{tabular}{|c|c|c|c|c|c|}
\hline Risk & Description & Risk area & $\begin{array}{l}\text { Concept type concerned / } \\
\text { affected }\end{array}$ & Probability & Impact type \\
\hline$R_{1}$ & $\begin{array}{l}\text { Traffic jam in urban area } \\
\text { at rush hour }\end{array}$ & Access/departure $\mathrm{Sit}_{3}$ & Tour's task of type of ride & $70 \%$ & Duration $+150 \%$ \\
\hline$R_{2}$ & Handler unavailable & $\begin{array}{l}\text { Loading/unloading to } \\
\text { Sit }_{2} \text { between } 10 \mathrm{~h} 00 \text { and } \\
10 \mathrm{~h} 30\end{array}$ & $\begin{array}{l}\text { Tour's task of type of } \\
\text { loading/unloading }\end{array}$ & $80 \%$ & $\begin{array}{l}\text { Duration }+20 \mathrm{mn} \\
\text { Driver provides loading/ } \\
\text { unloading } \rightarrow \text { additional } \\
\text { driver fatigue }\end{array}$ \\
\hline$R_{3}$ & $\begin{array}{l}\text { Bad indication to the loca- } \\
\text { tion of the goods delivery } \\
\text { on the } \text { Sit }_{1}\end{array}$ & Sit $_{1}$ & $\begin{array}{l}\text { Tour's task of type of } \\
\text { loading/unloading }\end{array}$ & $50 \%$ & Duration $+15 \mathrm{~min}$ \\
\hline
\end{tabular}

truck, takes his break at that time.The risk $R_{3}$ expresses the possibility that a driver does not know the localisation where goods need to be delivery just for the Sit $_{1}$.

In a complementary manner, the constraints of the transport company, inherited from legal and regulatory constraints require that:

- Time allowed for a tour does not exceed 5h;

- Driving periods shall not exceed not $1 \mathrm{~h}$;

- The autonomy of electical vehicle is $4 \mathrm{~h}$.

\section{B. Results and discussion}

To comply with the orders to be processed and any eventual constraints, for example it's an obligation to go at the delivery point Sit $_{3}$ before the delivery point Pli4, there are 40 solutions for the tour. A part of this 40 solutions are shown in Table IV. This table shows the succession of points to visit, starting from the warehouse $W_{1}$ and go back to the warehouse $W_{1}$.

The initial schedule proposed for the solution $S_{1}$ is shown in Figure 4, it shows the details of the solution $S_{1}$, indicating for each activity required:

- Its type: start, driving loading, unloading, ending of the tour when come back at the warehouse;

- Duration of each activity ;

- The activity's start time.

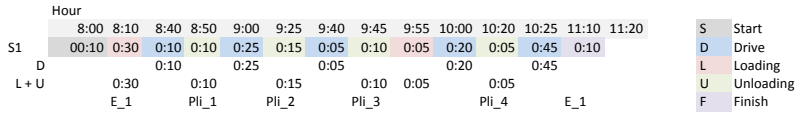

Figure 4. Example of planning for the solution S1

This solution can be characterized by many criteria:

- Time allowed;

Table III

LIST OF ORDERS

\begin{tabular}{cccccc} 
Order & Origin & Dest. & Loading time & Unloading time & Time window \\
\hline$O_{1}$ & $W_{1}$ & Sit $_{1}$ & - & $00 \mathrm{~h} 10$ & {$[8 \mathrm{~h}-13 \mathrm{~h}]$} \\
$\mathrm{O}_{2}$ & $W_{1}$ & Sit $_{2}$ & - & $00 \mathrm{~h} 15$ & {$[8 \mathrm{~h}-11 \mathrm{~h}]$} \\
$\mathrm{O}_{3}$ & $W_{1}$ & Sit $_{3}$ & - & $00 \mathrm{~h} 10$ & {$[8 \mathrm{~h}-13 \mathrm{~h}]$} \\
$\mathrm{O}_{4}$ & Sit $_{3}$ & Sit $_{4}$ & $00 \mathrm{~h} 05$ & $00 \mathrm{~h} 05$ & {$[10 \mathrm{~h}-13 \mathrm{~h}]$} \\
\hline
\end{tabular}

Table IV

SOLUTIONS TO REALIZE DELIVERY ORDERS

\begin{tabular}{cccccccc} 
Solution & \multicolumn{1}{c}{} \\
\hline$S_{1}$ & $V_{1}$ & $W_{1}$ & Sit $_{1}$ & Sit $_{2}$ & Sit $_{3}$ & Sit $_{4}$ & $W_{1}$ \\
& $V_{2}$ & - & - & - & - & - & - \\
$\ldots$ & $\ldots$ & $\ldots$ & $\ldots$ & $\ldots$ & $\ldots$ & $\ldots$ & $\ldots$ \\
$S_{20}$ & $V_{1}$ & $W_{1}$ & Sit $_{1}$ & Sit $_{2}$ & $W_{1}$ & - & - \\
& $V_{2}$ & $W_{1}$ & Sit $_{3}$ & Sit $_{4}$ & $W_{1}$ & - & - \\
$S_{21}$ & $V_{1}$ & - & - & - & - & - & - \\
& $V_{2}$ & $W_{1}$ & Sit $_{1}$ & Sit $_{2}$ & Sit $_{3}$ & Sit $_{4}$ & $W_{1}$ \\
$\ldots$ & $\ldots$ & $\ldots$ & $\ldots$ & $\ldots$ & $\ldots$ & $\ldots$ & $\ldots$ \\
$S_{40}$ & $V_{1}$ & $W_{1}$ & Sit $_{3}$ & Sit $_{4}$ & $W_{1}$ & - & - \\
& $V_{2}$ & $W_{1}$ & Sit $_{1}$ & Sit $_{2}$ & $W_{1}$ & - & - \\
& & & & & & &
\end{tabular}

- The maximum driving time;

- Total driving time;

- Autonomy of the vehicle $V_{1}$;

- Total time for loading and unloading;

- Environmental impact of the solution.

In the example discussed in this article, only some of these criteria are implemented and associated values are take in consideration.

From these results, the solutions do not respect the constraints set forth above may be dismissed: respect of the maximum amplitude of 4 hours, etc...

For the second step of the proposal three risks are created. Eight risk scenarios may occur:

- None risk: $S c R$

- Only the risk $R_{1}$ occurs: $S c R_{R_{1}}$;

- Only the risk $R_{2}$ occurs: $S c R_{R_{2}}$;

- Only the risk $R_{3}$ occurs: $S c R_{R_{2}}$;

- Risks $R_{1}$ and $R_{2}$ occur on the same tour: $S c R_{R_{1}, R_{2}}$;

- Risks $R_{1}$ and $R_{3}$ occur on the same tour: $S c R_{R_{1}, R_{3}}$;

- Risks $R_{2}$ and $R_{3}$ occur on the same tour: $S c R_{R_{2}, R_{3}}$;

- Risks $R_{1}$ and $R_{2}$ and $R_{3}$ occur on the same tour: $S c R_{R_{1}, R_{2}, R_{3}}$.

Each senario have a probability of occurence describe in the (Table VI). This probability is calcul with different value of all potenciel risk.

To simplify indicators calcul we propose in first time to considere that the time allowed is the cost, the driving time by the vehicle $V_{2}$ is the environmental impact and the driving time is the indicator of health and sécurity. On these first results, 
Table V

INFLUENCE OF RISKS ON GENERATED SOLUTIONS

\begin{tabular}{c|c|c|c|c|c|c|c|c|} 
& $S c R:$ & $S c R: R_{1}$ & $S c R: R_{2}$ & $S c R: R_{3}$ & $S c R: R_{1} ; R_{2}$ & $S c \mathrm{R}: R_{1} ; R_{3}$ & $S c \mathrm{R}: R_{2} ; R_{3}$ & $S c \mathrm{R}: R_{1} ; R_{2} ; R_{3}$ \\
\hline Solution & Validity & Validity & Validity & Validity & Validity & Validity & Validity & Validity \\
\hline$S_{2}$ & Yes & No & Yes & Yes & No & No & No & No \\
$S_{1} 8$ & Yes & No & Yes & Yes & No & No & Yes \\
$S_{4} 0$ & Yes & Yes & Yes & Yes & Yes & No & Yes
\end{tabular}

Table VI

SCENARIO PROBABILITY

\begin{tabular}{cc} 
Scenario & Occurence $(\%)$ \\
\hline$S c R:$ & 3 \\
$S c R: R_{1}$ & 7 \\
$S c R: R_{2}$ & 12 \\
$S c R: R_{3}$ & 3 \\
$S c \mathrm{R}: R_{1} ; R_{2}$ & 28 \\
$S c \mathrm{R}: R_{1} ; R_{3}$ & 7 \\
$S c \mathrm{R}: R_{2} ; R_{3}$ & 12 \\
$S c \mathrm{R}: R_{1} ; R_{2} ; R_{3}$ & 28 \\
\hline
\end{tabular}

Table VII

SOLUTIONS CHOSE BY THE PLANNER

\begin{tabular}{cccccccc} 
Solution & & & & & & \\
\hline \multirow{2}{*}{$S_{2}$} & $V_{1}$ & $W_{1}$ & Sit $_{1}$ & Sit $_{3}$ & Sit $_{4}$ & Sit $_{2}$ & $W_{1}$ \\
& $V_{2}$ & - & - & - & - & - & - \\
\hline \multirow{2}{*}{$S_{18}$} & $V_{1}$ & $W_{1}$ & Sit $_{3}$ & Sit $_{4}$ & Sit $_{2}$ & $W_{1}$ & - \\
& $V_{2}$ & $W_{1}$ & Sit $_{1}$ & $W_{1}$ & - & - & - \\
\hline \multirow{2}{*}{$S_{40}$} & $V_{1}$ & $W_{1}$ & Sit $_{3}$ & Sit $_{4}$ & $W_{1}$ & - & - \\
& $V_{2}$ & $W_{1}$ & Sit $_{1}$ & Sit $_{2}$ & $W_{1}$ & - & - \\
\hline
\end{tabular}

the planner have a lot of indicator to select few scenario as presented in the (Figure 1) step 3. To illustrate the robustess we chose three solutions $S_{2}, S_{18}$ and $S_{40}$ (Table VII). $S_{2}$ is at first glance a good solution on the environmental indicartor because the planning is realized also by a electrical vehicle. $S_{40}$ is better than the solution $S_{2}$ on the health and security indicator because the repartion of the delivery is balanced. $S_{18}$ is maybe chose for find a compromise between all solution.

Table V shows for each scenario, the same verification of the compliance constraints can thus be performed, as shown by the columns "validity".

Table VIII

SENSIBILITY OF SOLUTIONS TO DISTURBANCES

\begin{tabular}{ccc} 
Solution & Robustness & Preferred solution \\
\hline$S_{2}$ & 0.18 & \\
$S_{18}$ & 0.3 & \\
$S_{40}$ & 0.65 & $\mathrm{X}$ \\
\hline
\end{tabular}

Finally, the aggregated criteria of measure of the probability to respect constraints is calculated as shown in Table VIII. The solution $S_{2}$, previously identified as the best solution on the environemental level to be highly sensitive to disturbances: $82 \%$ of chance to not respect the constraints often the constraint doesn't respected was the autonomy of the vehicle but the time allowed at the tour is also exceeded. For solutions $S_{18}$ and $S_{40}$ they are not valide on few senario only cause by the autonomy of vehicle. The same solution with vehicle $V_{1}$ and $V_{2}$ swap will be a robust solution.

The robustness is an other indicator to help the planner to chose an appropriated solution. It's not because a solution is considerate less robust than an other that it is not possible to chose it. The Planner need to realize a lot of compromise and the robustness has to aim to help him in this chose. The robustness shows the solution unstable but this shows also that the first vision of indicator can be unstable and this view should be change the chose of the planner.

\section{CONCLUSION}

In the planning process, planners are generally facing with lack of indicators that are used to detremine the influnece of the risk on choosing the solution. In addition in these problems, there is a complexity which originates from the impact of risks on the genration of the solutions while trying to satisfy constraints and modify indicators of the first solution. In this study, we proposed a model and a generic approach to help the planners with better evaluation and comparasion of the obtained oriented solutions. For this purpose, we propose a set of indicators that are used to characterize each of the solutions. In a complementary manner, and to reflect the dynamic and stochastic character of execution environment of tours, we present an indicator that determines the robustness of the solutions. This indicator expresses the ability of the solution to respect the framework of constraints despite potential disruptions. We plan to continue the definition of indicators by adding precision, particularly using different ways of weighting the various solutions outside of framework. For example, a solution that does not respect one of the identified constraints will have a different weight of another solution by not observing none constraints.

\section{REFERENCES}

[1] T.-H. Nguyen, F. Marmier, and D. Gourc. "A decisionmaking tool to maximize chances of meeting project commitments". In: International Journal of Production Economics 142.2 (Apr. 2013), pp. 214-224 (cit. on p. 2).

[2] F. Marmier, D. Gourc, and F. Laarz. "A risk oriented model to assess strategic decisions in new product development projects". In: Decision Support Systems 56 (2013), pp. 74-82 (cit. on p. 2).

[3] F. Marmier, I. Filipas-Deniaud, and D. Gourc. "Strategic decision-making in NPD projects according to risk: application to satellites design projects". In: Computers in Industry published online (2014) (cit. on p. 2). 
[4] PMI. PMBOK Guide, Fifth Edition. 2013 (cit. on p. 2).

[5] J. Tixier, G. Dusserre, O. Salvi, and D. Gaston. "Review of 62 risk analysis methodologies of industrial plants". In: Journal of Loss Prevention in the Process Industries 15.4 (July 2002), pp. 291-303 (cit. on p. 2).

[6] D. Gourc. "Vers un modèle général du risque pour le pilotage et la conduite des activités de biens et de services : Propositions pour une conduite des projets et une gestion des risques intégrées, Habilitation à Diriger des Recherches, Institut National Polytechnique de Toulouse". Habilitation à Diriger des Recherches. Institut National Polytechnique de Toulouse, 2006 (cit. on p. 2).

[7] S. Ward and C. Chapman. "Transforming project risk management into project uncertainty management". In: International Journal of Project Management 21.2 (Feb. 2003), pp. 97-105 (cit. on p. 2).

[8] B. Carter, T. Hancock, J. Morin, and N. Robin. Introducing RISKMAN: the European project risk management methodology. The Stationery Office, 1996 (cit. on p. 2).

[9] R. G. Cooper, S. J. Edgett, and E. J. Kleinschmidt. "New Product Portfolio Management: Practices and Performance". In: Journal of Product Innovation Management 16.4 (1999), pp. 333-351 (cit. on p. 2).

[10] E. Ferrario, N. Pedroni, and E. Zio. "Evaluation of the robustness of critical infrastructures by Hierarchical Graph representation, clustering and Monte Carlo simulation". In: Reliability Engineering \& System Safety 155 (Nov. 2016), pp. 78-96 (cit. on p. 2).

[11] M. T. Jensen. "Improving robustness and flexibility of tardiness and total flow-time job shops using robustness measures". In: Applied Soft Computing 1.1 (June 2001), pp. 35-52 (cit. on p. 2).

[12] J. M. Carlson and J. Doyle. "Complexity and robustness". In: Proceedings of the National Academy of Sciences 99 (Supplement 1 Feb. 2002), pp. 2538-2545 (cit. on p. 2).

[13] C. Foster. "Estimating Complex System Robustness from Dual System Architectures". In: Unifying Themes in Complex Systems. Ed. by A. Minai, D. Braha, and Y. Bar-Yam. Springer Berlin Heidelberg, 2010, pp. 527534 (cit. on p. 2).

[14] E. Jen. "Stable or robust? What's the difference?" In: Complexity 8.3 (Jan. 2003), pp. 12-18 (cit. on p. 2).

[15] S. Ali, A. A. Maciejewski, H. J. Siegel, and J.-K. Kim. "Definition of a robustness metric for resource allocation". In: Parallel and Distributed Processing Symposium, 2003. Proceedings. International. Apr. 2003, 10 pp.- (cit. on p. 2).

[16] SRA. SRA develops glossary of risk-related terms. Society for Risk Analysis: 2015. 2015 (cit. on p. 2).

[17] Z. Shi, E. Jeannot, and J. Dongarra. "Robust task scheduling in non-deterministic heterogeneous computing systems". In: IEEE, 2006, pp. 1-10 (cit. on p. 2).
[18] L.-C. Canon and E. Jeannot. "A Comparison of Robustness Metrics for Scheduling DAGs on Heterogeneous Systems". In: Proceedings of the 2007 IEEE International Conference on Cluster Computing. CLUSTER '07. Washington, DC, USA: IEEE Computer Society, 2007, pp. 558-567 (cit. on p. 2).

[19] L.-C. Canon and E. Jeannot. "Evaluation and Optimization of the Robustness of DAG Schedules in Heterogeneous Environments". In: IEEE Transactions on Parallel and Distributed Systems 21.4 (Apr. 2010), pp. 532-546 (cit. on p. 2).

[20] J. Smith et al. "Measuring the Robustness of Resource Allocations in a Stochastic Dynamic Environment". In: IEEE, 2007, pp. 1-10 (cit. on p. 2).

[21] V. Shestak, J. Smith, H. Siegel, and A. Maciejewski. "A Stochastic Approach to Measuring the Robustness of Resource Allocations in Distributed Systems". In: IEEE, 2006, pp. 459-470 (cit. on p. 2).

[22] R. Bastide et al. "Plas'O'Soins: A software platform for modeling, planning and monitoring homecare activities". In: IRBM 35.2 (Apr. 2014), pp. 82-87 (cit. on p. 2).

[23] D. Gourc, F. Marmier, and P. Gaborit. "An approach based on Tabu search technique for solving a multi time window home healthcare scheduling problem". In: Nov. 2014 (cit. on p. 3). 